\title{
Low back pain patients' perspectives on long-term adherence to home-based exercise programmes in physiotherapy
}

Citation for published version (APA):

Saner, J., Bergman, E. M., de Bie, R. A., \& Sieben, J. M. (2018). Low back pain patients' perspectives on long-term adherence to home-based exercise programmes in physiotherapy. Musculoskeletal science and practice, 38, 77-82. https://doi.org/10.1016/j.msksp.2018.09.002

Document status and date:

Published: 01/12/2018

DOI:

10.1016/j.msksp.2018.09.002

Document Version:

Publisher's PDF, also known as Version of record

Document license:

Taverne

Please check the document version of this publication:

- A submitted manuscript is the version of the article upon submission and before peer-review. There can be important differences between the submitted version and the official published version of record.

People interested in the research are advised to contact the author for the final version of the publication, or visit the DOI to the publisher's website.

- The final author version and the galley proof are versions of the publication after peer review.

- The final published version features the final layout of the paper including the volume, issue and page numbers.

Link to publication

\footnotetext{
General rights rights.

- You may freely distribute the URL identifying the publication in the public portal. please follow below link for the End User Agreement:

www.umlib.nl/taverne-license

Take down policy

If you believe that this document breaches copyright please contact us at:

repository@maastrichtuniversity.nl

providing details and we will investigate your claim.
}

Copyright and moral rights for the publications made accessible in the public portal are retained by the authors and/or other copyright owners and it is a condition of accessing publications that users recognise and abide by the legal requirements associated with these

- Users may download and print one copy of any publication from the public portal for the purpose of private study or research.

- You may not further distribute the material or use it for any profit-making activity or commercial gain

If the publication is distributed under the terms of Article $25 \mathrm{fa}$ of the Dutch Copyright Act, indicated by the "Taverne" license above, 
Original article

\title{
Low back pain patients' perspectives on long-term adherence to home-based exercise programmes in physiotherapy
}

\author{
Jeannette Saner ${ }^{\mathrm{a}, \mathrm{b}, *}$, Esther M. Bergman ${ }^{\mathrm{c}}$, Rob A. de Bie ${ }^{\mathrm{b}, \mathrm{d}}$, Judith M. Sieben ${ }^{\mathrm{b}, \mathrm{e}}$ \\ a Institute of Physiotherapy, School of Health Professions, Zurich University of Applied Sciences, Winterthur, Switzerland \\ ${ }^{\mathrm{b}}$ Care and Public Health Research Institute (CAPHRI), Maastricht University, Maastricht, the Netherlands \\ ${ }^{\mathrm{c}}$ Zuyderland Academy, Zuyderland Medical Center, Sittard-Geleen \& Heerlen, the Netherlands \\ d Dept. of Epidemiology, Maastricht University, Maastricht, the Netherlands \\ e Dept. of Anatomy and Embryology, Maastricht University, Maastricht, the Netherlands
}

\section{A R T I C L E I N F O}

\section{Keywords:}

Exercise therapy

Adherence

Movement control

Low back pain

Qualitative research

\begin{abstract}
A B S T R A C T
Background: Adherence to an exercise programme impacts the outcome of physiotherapy treatment in patients with non-specific low back pain.

Objectives: The aim of this study was to explore the patients' perspectives on long term adherence to such exercise programmes.

Design: This qualitative study was embedded in a randomised controlled trial (RCT) which compared the effectiveness of two types of exercise programme on patients with nonspecific low back pain.

Methods: Answers from 44 participants to three open-ended questions were analysed using thematic analysis. Results/findings: Patients' perceptions related to the following themes: 1) the role of knowledge in long-term exercise adherence; 2) strategies to support exercise adherence; 3) barriers to exercise adherence 4) the role of perceived effects of exercise.

Conclusions: Adherence to long-term exercise is supported through knowledge of the exercises and correct performance. A self-initiated training strategy is the most successful in the perception of participants. Individually supervised physiotherapy treatment that includes coaching towards strategies for post-treatment long term exercise behaviour is recommended.
\end{abstract}

\section{Introduction}

For home-based, unsupervised exercise programmes to be effective, patient adherence is of utmost importance but is hard to achieve. Adherence is defined as: "the extent to which a person's behaviour ... corresponds with agreed recommendations from a health care provider" (WHO, 2003). Different types of adherence in exercise have been investigated (e.g. times of attendance, numbers of exercises and quality of performance). Previous systematic reviews of qualitative and quantitative studies have described barriers to treatment adherence in populations with musculoskeletal problems (Bachmann et al., 2018; Jack et al., 2010), reviewed patients' perceptions towards exercise (Slade et al., 2014) and outlined interventions to improve adherence (Jordan et al., 2010). Large variations exist in the methods of assessing adherence to exercise (Hall et al., 2015; McLean et al., 2017). In patients with low back pain, adherence to prescribed home exercises is reported to be low, with some $50 \%-70 \%$ being non-adherent to exercise (Beinart et al., 2013). Patients generally show preference for a supervised exercise programme over receiving exercise advice alone (Slade et al., 2014). In patients with low back pain a large group is affected by non specific low back pain (NSLBP) where a specific cause of pain cannot be diagnosed (Airaksinen et al., 2006). It remains unclear, which strategies patients with NSLBP adopt in order to successfully continue to exercise on their own once supervised training in therapy sessions has ended. Adherence to exercise in this context may refer to selfreported exercise times as well as correct performance of exercise, integration in to daily life and more.

In a study among low back pain patients who participated in a stabilising exercise programme, increasing participants' knowledge and understanding was identified as a key theme in treatment (Sokunbi et al., 2010). Insufficient relevant information to patients has also been described as barrier to exercise adherence (Jack et al., 2010). However,

\footnotetext{
* Corresponding author. Zürcher Hochschule für Angewandte Wissenschaften, Departement Gesundheit, Institut für Physiotherapie, Technikumstrasse 71, Postfach, CH-8401, Winterthur, Switzerland.

E-mail addresses: jeannette.saner@zhaw.ch (J. Saner), e.bergman@zuyderland.nl (E.M. Bergman), ra.debie@maastrichtuniversity.nl (R.A. de Bie), j.sieben@maastrichtuniversity.nl (J.M. Sieben).
} 
Box 1

Short description of the RCT

Patients $(n=106)$ who participated in the RCT were randomised into two exercise groups (movement control exercise $=$ MC/n $=52$; general exercise $=\mathrm{GE} / \mathrm{n}=54$ ). Both groups were treated in individual treatment sessions of 30 min, ideally twice per week, over a period of nine to 12 weeks. Participants were strongly encouraged to exercise further at home over the following year. Fourteen physiotherapy clinics and practices in the German part of Switzerland participated in the RCT, while thirty-three therapists provided treatments. The concept of the MC treatment included a specifically tailored exercise programme directed at the diagnosed movement abnormalities, in order to eliminate these irregularities and normalise the movements. Initially, participants learned to control movements in closed chain positions, following which they progressed to open chain positions and increased loading. Posture and movement awareness were practised. Strength training was allowed once movement control had been achieved. In the GE group, the exercises were following a prescheduled standardised programme and aimed at improving general endurance and the strength of the lumbar and pelvic regions and legs.

Follow-up measurements were taken post-treatment, at six and 12 months. The primary outcome measurement was the Patient Specific Function Scale (PSFS); secondary measures were the Roland Morris Disability Questionnaire (RMDQ) and the Graded Chronic Pain Scale (GCPS) for disability and pain for all participants. The self-reported adherence to exercise was high, with $46 \%$ of the participants reporting doing the recommended exercises twice or more per week after one year.

the question remains as to which kind of knowledge is important and how patients successfully apply this knowledge in their daily lives on a long-term basis, and/or which factors prevent them from doing so.

We recently reported on a randomised controlled trial (RCT) (see Box 1) which tested the effectiveness of a specifically tailored exercise programme on patients diagnosed as suffering from NSLBP with movement control impairment (MCI) (Saner et al., 2015). MCI is a clinically diagnosed subgroup of NSLBP. It is defined as mechanically induced pain accompanied by movement abnormalities of the lumbar spine. The subgroup is assessed by means of a series of functional tests, as described by Luomajoki (Luomajoki et al., 2008, 2010). The RCT revealed no difference between the tailored exercise programme compared to a general exercise programme on all outcome measurements. However, both programmes resulted in significant improvements in function, disability and pain, which were retained over the course of one year following treatment. In this paper we report about the embedded qualitative data collection regarding treatment adherence.

This study explores the perspectives on adherence of patients with NSLBP and MCI who participated in either of two long term homebased exercise programmes. Specific focus is on the role of knowledge and understanding about exercise (as viewed by the patients) in the ability to apply a long-term, self-directed home exercise programme succesfully. What aspects of the physiotherapy programme do patients mention as important to foster adherence afterwards?

\section{Methods}

\subsection{Ethics}

The research was approved by the Swiss Ethics Committee (KEK-ZHNr: 2010-0034/5) and registered with Current Controlled Trials (ISRCTN80064281). All participants in the study were informed of the aim and the protocol of the study and gave their written consent. For reporting, we followed the COREQ (COnsolidated criteria for REporting Qualitative research) (Tong et al., 2007).

\subsection{Data collection}

The questionnaire used was part of the final follow-up assessment of the RCT, which took place one year after enrolment. Forms were sent out to the participants and returned by postal mail. Due to the large amount of other measurements, a comprehensive set of three openended questions was used. The creation of the questions based on results of a previously published focus group study in chronic LBP patients (Sokunbi et al., 2010). Sufficient space was provided for extensive answers:

Question 1: "Describe if and how the physiotherapy treatment helped you in the past year"

Question 2: "What did you learn in your physiotherapy treatment? Describe in your own words."

Question 3: "Describe if and how you implemented your new knowledge in your daily life. Describe in your own words."

The return process was supported through a reminder via telephone contact by a research assistant.

\subsection{Data analysis}

Coding was carried-out by three of the authors, JS1 (physiotherapist, primary researcher of the RCT), EB ( $\mathrm{PhD}$, human movement scientist, independent researcher) and JS2 (PhD, human movement scientist, RCT supervisor).

Data was evaluated using thematic analysis (Braun et al., 2016; Braun, 2014; King, 2011).

An initial categorising system was established by JS1 based on literature and was used for the preliminary template of themes (Jack et al., 2010; McLean et al., 2010; Slade et al., 2014; Sokunbi et al., 2010). All three researchers were in agreement. A sample of 10 questionnaires were read and re-read separately by JS1, EB and JS2, who identified new themes and sub-themes. These (sub) themes were discussed and a code list was created. Another 3 sets of 10 questionnaires were coded and agreed on in alternating pairs of coders. Using this process the final coding list was developed.

The final coding list was used to code the questionnaires of participants from various clinical settings and both treatment groups, including recoding the questionnaires used to create the coding list. Coding led to little disagreement and consensus was always reached through discussion.

Atlas.ti 7.0 was used for analysis.

\subsection{Sampling}

Due to logistic reasons, qualitative data collection started not earlier than with the inclusion of the seventh RCT participant. Since then, all participants were requested to complete the questionnaire. The remaining questionnaires were included for analysis and after coding and discussing 44 consecutive questionnaires saturation was reached (Patient no 7-65). Fourteen participants in this series did not respond or withdrew from the study. 
Table 1

Baseline characteristics of participants taking part in qualitative research design and full sample of the randomised controlled trial.

\begin{tabular}{|c|c|c|c|c|c|c|}
\hline & \multicolumn{2}{|l|}{ MC } & \multicolumn{2}{|l|}{ GE } & \multicolumn{2}{|l|}{ Both groups } \\
\hline & Qualitative sample & Total RCT & Qualitative sample & Total RCT & Qualitative sample & Total RCT \\
\hline $\mathrm{n}$ & 18 & 52 & 26 & 54 & 44 & 106 \\
\hline Gender, female, $\mathrm{n}$ & 8 & 16 & 11 & 24 & 19 & 40 \\
\hline Age, y, mean (SD) & $43.1(12.5)$ & $42.8(13.8)$ & $44.9(13.9)$ & 40.5 (14.7) & $44.2(13.1)$ & $41.6(14.1)$ \\
\hline Pain duration, $y$, mean & 11 & 11.6 & 8 & 8.4 & 9.5 & 10.0 \\
\hline \multicolumn{7}{|l|}{ Sport participation n (\%) } \\
\hline no sports & $8(44.5 \%)$ & $19(36.5 \%)$ & $7(26.9 \%)$ & $16(29.6 \%)$ & $15(34.1 \%)$ & $35(33.1)$ \\
\hline $1-2 \times$ per week & $6(33.5 \%)$ & $21(40.4 \%)$ & $11(42.3 \%)$ & $23(42.6 \%)$ & $17(38.6 \%)$ & $44(41.5 \%)$ \\
\hline$>2 \times$ per week & $4(22.2 \%)$ & $10(19.2 \%)$ & $6(23.1 \%)$ & $13(24.1 \%)$ & $10(22.7 \%)$ & $23(21.7 \%)$ \\
\hline PSFS mean (SD) & $5.9(2.1)$ & $4.3(1.9)$ & $6.4(2.0)$ & $4.0(2.0)$ & $6.1(2.0)$ & $4.2(2.0)$ \\
\hline RMDQ mean (SD) & $9.7(3.2)$ & $9.1(3.2)$ & $8.9(4.1)$ & $8.2(3.3)$ & $9.25(3.8)$ & $8.6(3.3)$ \\
\hline
\end{tabular}

MC: Movement control group GE: General exercise group.

PSFS: Patient-Specific Functional Scale self-score activity mentioned first, ranging from 0 (unable to perform) to 10 (able to perform without difficulties). RMDQ: Roland Morris Disability Questionnaire score, ranging from 0 (no difficulties) to 24 (extreme difficulties).

SD: standard deviation.

\section{Results}

\subsection{Participants}

The sample of 44 participants $(\mathrm{MC}=19 ; \mathrm{GE}=25$ ) represents $41 \%$ of the 106 participants in the RCT. See Table 1 for participant characteristics.

The median age of the qualitative sample was 44 years; mean pain duration of NSLBP was 9.5 years. Baseline assessment showed a mean disability of 6.1 (scale $0-10$, lower score means greater disability) as measured by the Patient-Specific Functional Scale (PSFS) and a score of 9.25 (scale 0-24, higher score means greater disability) on the Roland Morris Disability Questionnaire (RMDQ)(Roland and Morris, 1983; Stratford et al., 1995). Characteristics of the qualitative sample showed no notable differences to the total RCT sample (Saner et al., 2015). Also both groups (MC and GE) were found to be largely similar, with the only difference being sports participation at baseline, with more MC participants reporting "no sport" ( $\mathrm{MC}=44.5 \%$; $\mathrm{GE}=26.9 \%)$.

As described above, all participants in the RCT were encouraged to do their recommended exercises at least twice per week over the course of the follow-up year. As we previously published, one year after enrolment $46 \%$ of all participants in the RCT reported that they had adhered to this exercise frequency or even exercised more often (Saner et al., 2015). We also reported patients' satisfaction with their treatment after one year was rated high to very high ( 8 or more on an 11 point Likert scale) by $80 \%$ of the participants (Saner et al., 2015).

Of the 44 coded participants in the qualitative sample three did not answer question no. 1, one did not answer question no. 2 and four did not answer question no. 3 . The answers in general were short sentences with exceptions ranging from short cues to extensive texts.

During the period of getting familiar with the gathered data, it became clear that participants reported several aspects of adherence to exercise. It is not uncommon in qualitative research that unexpected themes emerge from the data. Therefore, the evaluation of the qualitative data led to four major themes related to exercise performance and adherence: the role of knowledge in long-term adherence to exercise; strategies to support exercise adherence; barriers to exercise adherence; and the role of the perceived effects of treatment. The results for each theme are presented below with illustrative quotes. Participants are identified by the ID codes of the RCT and group allocation (Patient 25 refers to the 25th participant enrolled, GE refers to General Exercise group, MC refers to Movement Control group).

\subsubsection{The role of knowledge in long-term adherence to exercise}

This theme refers to participants' accounts of how knowledge about exercise was perceived; as well as to which knowledge, in their opinion, remained of interest after one year and whether it had an impact on exercise adherence.

Participants regarded the perceived relevance of exercise as their main knowledge gain. They learned by experience about the association between exercise and the prevention/resolution of their back problems. Some participants clearly drew an association between gained knowledge, exercise and self-reported adherence/non-adherence to exercise.

"If I do my exercises regularly, I don't have low back pain. As soon as I become negligent, low back pain returns." (Patient 25, GE)

"As soon as I feel my back, I know which exercises I have to do in order to get rid of it." (Patient 7, MC)

Patients in both groups described learning certain exercises, which they perceived as targeting their problem, as a knowledge enhancement.

"I learned, to feel/to train the low back muscles goal-oriented and intensive." (Patient 46, GE)

"The exercises have to be targeted at my problem and not following a randomly applied scheme." (Patient 31, MC)

"I do goal-oriented exercises once a week." (Patient 17, MC)

Knowing the correct performance of the exercises was a highly valued learning effect to all participants and supported their confidence in home exercising. Several participants mentioned the importance of training under the guidance of the physiotherapist; the repetitions and corrections increased their knowledge of the exercises. Participants in the GE group reported that they had learned new exercises.

"I received precise instructions on how to perform the exercise" (Patient 34, MC)

"I trained the correct performance of the exercise." (Patient 25, GE)

"I got to know new exercises." (Patient 20, GE)

"We created a simple exercise plan together." (Patient 25, GE)

A good knowledge of the factors which aggravated their low back pain was frequently reported by all participants. Amongst other factors, sitting and lifting heavy loads were mentioned. The GE group participants referred more to strength training to overcome their deficits; the MC participants showed a trend towards regarding movement as better than static loading. These arguments are in line with the recommendations in the respective training programmes.

"I learned that strengthening the abdominal and back muscles is important." (Patient 61, GE) 
"I learned that movement helps. Sitting is not good." (Patient 38, $\mathrm{MC)}$

"I learned the correct behaviour and movement." (Patient 67, MC)

"I broke with the habit of sitting incorrectly. I learned the correct way of lifting loads. I listen to my back more often and end activities earlier, if they burden my back." (Patient 13, GE)

Interestingly, knowledge of their diagnosis, possible causes of LBP or detailed knowledge of anatomy was not mentioned by any participant.

\subsubsection{Strategies to support exercise adherence}

Given that participants had learnt new knowledge or skills, we were interested to learn how and how often they were applying them; which strategies they had developed to include their exercise programmes into their daily lives.

Of general importance for the participants to be able to include their exercises into daily life appeared to be the simplicity of the exercises. They mentioned that the exercises were easy to perform at home and needed no additional equipment.

"I can repeat the exercises during the day. They are simple, but very efficient." (Patient 24, MC)

"The exercises shown can easily be done at home." (Patient 44, GE)

A self-initiated participation in some form of structured, organised training helped participants to perform the exercises on a regular basis over the course of the year. This strategy was reported by a high number of participants and, it should be noted, that this advice was not part of the study protocol. Regularity in performing the exercises was often mentioned, together with discipline. The combination of general training and specific exercises made it easier to maintain discipline and acted as a reminder to do the exercises. They included their own exercises into other programmes of general fitness, back classes or general activity groups.

"If possible (absences) I visit a strength training twice per week." (Patient 51, GE)

"I perform back stability exercises in my fitness training 2-3 times a week. This is what I need." (Patient 27, MC)

"I can do the exercises during my jogging in the forest." (Patient 48, $\mathrm{GE)}$

"I include them in sports $(2 \times$ back training, $1 \times$ nordic walking per week)." (Patient 34, MC)

The vast majority of participants mentioned the positive impact of the physiotherapy treatment on the correct performance of daily tasks. It became clear that participants applied the new knowledge into active changes. Comments often mentioned a change of the body posture and achieved ergonomic changes. While participants in the GE group mentioned the correct performance of activities more often, the participants in the MC group reflected more often on improvement of their body posture. Several mentioned that they followed the general advice to sit, stand and lift correctly. Retaining a good posture in aggravating situations was perceived as a benefit.

"I take care of how I walk and sit." (Patient 36, GE)

"I'm standing the whole working day, I'm using a step now, where I can relax my legs." (Patient 54, MC)

"I'm more conscious of my posture, this means to correct it." (Patient 35, GE)

"I'm standing more consciously and also more relaxed." (Patient 43, MC)

Only in the GE group was the implementation of physical training into daily life perceived as increased general physical activity. They directly connected the physiotherapy intervention to their more active life style.

"I also do more sports and think this helps my back too." (Patient 47, GE)

"I climb stairs instead of using the lift or escalator." (Patient 20, GE)

\subsubsection{Barriers to exercise adherence}

Only a few participants actually reported inconsistent or absent exercise behaviour and the connection to possible barriers. This could be due to the fact that we did not explicitly ask for difficulties or barriers in the questionnaire. However, a few spontaneously mentioned lack of time and motivation, forgetting to do or difficulties to include the exercises into their daily activities.

"I should take more time to do exercises." (Patient 42, MC)

"Rarely applicable, my possibilities to move are limited to work space, coffee area and WC." (Patient 38, MC)

"I can follow it partially, but I keep forgetting it from time to time." (Patient 21, MC)

One participant mentioned that he/she can't remember the exercises.

"I can't remember which exercise I should do." (Patient 56, GE)

Two participants mentioned that they no longer do their exercises without specifying a reason.

\subsubsection{The role of perceived effects of treatment}

This theme looks at which effects of treatment were important to the participants and the connection between the perceived effects of the treatment and adherence to exercise afterwards.

Most often mentioned by our participants was physical "gain", described as: more muscle strength, elasticity or relaxation.

"I have the feeling, that my back is stronger and I notice it in my work." (Patient 47, GE).

"After treatment I very often had a good feeling in my back (relaxed low back and increased tabulator flexibility)." (Patient 10, GE).

If our participants described physical relief they always mentioned pain. Apparently, and understandably, this was the major symptom of importance.

"When I started the therapy, it helped me a lot. At the end I was pain free." (Patient 23, MC)

"It did help me a lot, after the treatment my back pain only returned 1-2x per month." (Patient 29, GE)

The perceived effect of pain relief during treatment is a major motivator for exercise adherence.

"As soon as I notice my back, I know exactly which exercises I have to do to abolish my pain." (Patient 7, MC)

"It is good to quickly do the exercises, as soon as I feel the first signs of pain." (Patient 54, MC)

Some participants reported only a very limited, short term effect of the treatment on their pain.

"The exercises helped for a very short time only." (Patient 14, MC)

"Good during the therapy sessions, but no remarkable long-term effect." (Patient 18, GE)

Two participants directly connected the limited effect to their nonadherence to exercise.

"Unfortunately not much effect, because I don't remember the 


\section{exercises." (Patient 56, MC)}

The perception of no effect on their pain was reported by three participants. They discontinued the exercises but kept in mind some advice from the therapy sessions.

"Did not help at all. If my back pain gets worse, I move more consciously as my physiotherapist recommended." (Patient 15, GE)

"Didn't help, pain still the same. I improved my posture." (Patient 49, MC)

\section{Discussion}

A better insight into patients' perceptions of their experiences with exercise programmes for NSLBP may help to focus future physiotherapy treatments on factors supporting long-term adherence to exercise. No crucial differences were encountered between the accounts of participants in the two treatment groups. The results of this study point to gained knowledge about exercises as important and revealed the insight, that a combination of recommended exercises with a self-initiated physical activity being a successful strategy to maintain adherence in the view of the participants. These findings might explain the RCT results of both groups improving considerably.

\subsection{Confidence about the exercises and their performance is important}

The importance of knowledge about and perceived effectiveness of exercises as reported by our participants might be related to the construct of confidence. 'Confidence' can be described as belief in oneself and one's abilities. If increased knowledge and perceived effects lead to raised confidence in own abilities, these steps would subsequently explain the high adherence rate in this study (Borsbo et al., 2010; Costa Lda et al., 2011). Our participants appeared to have gained confidence on several levels of perception: firstly, they highly valued the introduction to new exercises, the corrections and the control by their physiotherapist; secondly, their confidence increased due to the perceived effects of the exercises - the main perceived effects were physical gains, such as increased muscle power, flexibility, relaxation and general physical fitness; thirdly, participants noticed an association between the regular performance of exercises and less back pain; and lastly, confidence and security in the performance of their daily tasks was also increased.

Lack of confidence about the correct performance of exercises has been described previously as a main barrier to successful adherence (Escolar-Reina et al., 2010; Jack et al., 2010; Palazzo et al., 2016; Slade et al., 2009; Slade et al., 2014). Patients need confidence about how to correctly perform exercises and, therefore, require the support of trained instructors (Escolar-Reina et al., 2010; Palazzo et al., 2016; Slade et al., 2014; Sokunbi et al., 2010). This study supports these findings. Easily-learned exercises were also easier to perform at home. As soon as the performance of exercises was connected to a perceived positive effect, our participants developed strategies to adhere to the programme. The same pattern applies to the knowledge of aggravating factors and the performance of the activities of daily life. Knowledge and individual successful experiences lead to behavioural change. A recent study with a protocol similar to the present study, rated the effect of performance in everyday life even higher than the applied exercises (Van Dillen et al., 2016). This raises the question as to whether an additional behavioural approach would be beneficial. We agree with O'Keefe et al. (2016), who compared the effects of physical interventions with behavioural/psychological informed interventions and combined interventions in a meta-analysis. They found no clinically important difference and commented that "the decision to choose a combined intervention should be balanced against the time and resources available" (O'Keeffe et al., 2016). Participants in the present study were able to successfully develop strategies to confidently change their performance in daily life after following simple instructions and experiencing the benefits. Additional behavioural treatment modalities may in that case not be necessary.

\subsection{Individualised approach counts}

Participants perceived the exercises as individualised to their life situation and targeted to their back pain problem. These factors help to improve adherence to exercise (Beinart et al., 2013; Jack et al., 2010; Jordan et al., 2010; McLean et al., 2010; Palazzo et al., 2016; Slade et al., 2009; Slade et al., 2014). The fact that participants in both groups reported perceived individualisation, when in reality the GE group followed a pre-set programme, gives rise to the speculation that patients and physiotherapists have different concepts of individualisation. Apparently, one-on-one treatment is perceived as individualisation by the patient, despite the fact that the exercises may be predefined and the same for everyone. Participants described a certain pride in being able to perform their exercises correctly, regularly and with discipline, and also relating their new behaviour and their recognition of the aggravating factors. But it seems that which kind of exercises they should be doing is of no importance to them. It is the physiotherapist who makes this decision. It may be the way how the instructions to do the exercises are imparted which leaves an individualised impression, rather than the choice of exercises itself. The often overlooked therapistpatient relationship and communications skills can make a difference to successful adherence (Miciak et al., 2012; O'Sullivan et al., 2016).

\subsection{Self-organised training helps}

Strategies to overcome barriers to adherence, such as a perceived lack of self-discipline, lack of time or forgotten exercises, vary. A key finding of this study is, that many participants mentioned the inclusion of the exercises into a self-initiated and self-organised physical training format. Some trained in groups, some in individual fitness sessions and others in sports activities such as jogging or walking. These results correspond with findings of recently published studies regarding exercise programs for NSLBP patients (Palazzo et al., 2016; Slade et al., 2014). Coaching patients at the end of physiotherapy training to find an appropriate and feasible long-term commitment to physical training helps to adhere to the prescribed exercises. Furthermore, a good coaching process initiates self-efficacy and independence from medical interventions; these personal attributes have been associated with positive treatment outcome (Bunzli et al., 2016).

Adherence and its' long term barriers and strategies have been researched in other fields of physiotherapy as for example in pelvic floor muscle exercises (PFME) (Frawley et al., 2015). For PFME a survey amongst other data revealed long term patient related factors influencing adherence. A lack of motivation and forgetting to do the exercises were reported as barriers and use of cues to remember to do exercises as a successful strategy. This latter information that patients should implement routines to do the exercises did also appear in the answers of our long term low back exercise programmes, with the addition to selfinitiate these routines.

\subsection{Clinical implications}

On the basis of the perceptions of our participants we recommend that exercise programmes should include easy to perform exercises as part of supervised training until the patient gained the knowledge on why and how to perform these exercises. They wish to feel confident to continue by themselves. Participants gain a positive association to the exercises if they perceive a positive effect on their complaints. Self-initiated physical training combined with the specific exercises helps to overcome barriers in long term performance, and should therefore be stimulated by the physiotherapist. 


\subsection{Strength and limitations}

The present study provides insight into long-term exercise programmes. However, participants received additional support through the procedures of the RCT. Phone calls, which were mainly aimed at optimising data collection, may have given additional encouragement to continue with the exercise instructions. Furthermore, we can only report the results of participants who finished the RCT and our results may be prone to some selection bias. Lastly, our results are based on self-reported written data which did not allow further elaboration. Interviews with participants may have led to further insights, however the multicentre RCT design did not allow for this method of data collection. In terms of generalisability, this data applies to patients with NSLBP who were motivated enough to actively participate in an RCT focusing on exercise. It could be of interest for future research to explore whether the reported factors also apply to other conditions which require regular exercise and to populations who are not particularly interested in exercising.

Embedding qualitative research into RCTs generates a deeper understanding of the working mechanisms of health interventions (O'Cathain et al., 2013). The present study describes contextual findings which can be of use in other exercise treatments and future trials as well.

\section{Conclusion}

The results of this study indicate that, according to our participants, gaining the confidence to exercise correctly has a high impact on longterm adherence to exercise. Easily-performed exercises brought them noticeable benefits and supported their adherence to the exercises and influenced performance in their everyday life on a long-term basis. A better adherence to long-term exercise appears to be achieved by the inclusion of the exercises into a self-initiated training regimen. Future therapies should include coaching towards this strategy.

\section{Acknowledgement}

The project was supported by Swiss National Science Foundation.

\section{References}

Airaksinen, O., Brox, J., Cedraschi, C., Hildebrandt, J., Klaber-Moffett, J., Kovacs, F., et al., 2006. Chapter 4. European guidelines for the management of chronic nonspecific low back pain. Eur. Spine J. 15 (Suppl. 2), S192-S300.

Bachmann, C., Oesch, P., Bachmann, S., 2018. Recommendations for improving adherence to home-based exercise: a systematic review. Phys. Med. 28, 20-31.

Beinart, N.A., Goodchild, C.E., Weinman, J.A., Ayis, S., Godfrey, E.L., 2013. Individual and intervention-related factors associated with adherence to home exercise in chronic low back pain: a systematic review. Spine J. 13, 1940-1950.

Borsbo, B., Gerdle, B., Peolsson, M., 2010. Impact of the interaction between self-efficacy, symptoms and catastrophising on disability, quality of life and health in with chronic pain patients. Disabil. Rehabil. 32, 1387-1396.

Braun, V., Clarke, V., Moller, N., 2016. I'm gonna tell you a story: exploring the pitfalls and possibilities of qualitative story completion methods. Int. J. Qual. Meth. 15.

Braun VC, V., 2014. Successful Qualitative Research: a Practical Guide for Beginners Sage, London.

Bunzli, S., McEvoy, S., Dankaerts, W., O'Sullivan, P., O'Sullivan, K., 2016. Patient perspectives on participation in cognitive functional therapy for chronic low back pain. Phys. Ther. 96, 1397-1407.

Costa Lda, C., Maher, C.G., McAuley, J.H., Hancock, M.J., Smeets, R.J., 2011. Self-efficacy is more important than fear of movement in mediating the relationship between pain and disability in chronic low back pain. Eur. J. Pain 15, 213-219.
Escolar-Reina, P., Medina-Mirapeix, F., Gascon-Canovas, J.J., Montilla-Herrador, J., Jimeno-Serrano, F.J., de Oliveira Sousa, S.L., et al., 2010. How do care-provider and home exercise program characteristics affect patient adherence in chronic neck and back pain: a qualitative study. BMC Health Serv. Res. 10, 60.

Frawley, H.C., McClurg, D., Mahfooza, A., Hay-Smith, J., Dumoulin, C., 2015. Health professionals' and patients' perspectives on pelvic floor muscle training adherence2011 ICS State-of-the-Science Seminar research paper IV of IV. Neurourol. Urodyn. 34, 632-639.

Hall, A.M., Kamper, S.J., Hernon, M., Hughes, K., Kelly, G., Lonsdale, C., et al., 2015. Measurement tools for adherence to non-pharmacologic self-management treatment for chronic musculoskeletal conditions: a systematic review. Arch. Phys. Med. Rehabil. 96, 552-562.

Jack, K., McLean, S.M., Moffett, J.K., Gardiner, E., 2010. Barriers to treatment adherence in physiotherapy outpatient clinics: a systematic review. Man. Ther. 15, 220-228.

Jordan, J.L., Holden, M.A., Mason, E.E., Foster, N.E., 2010 Jan. Interventions to improve adherence to exercise for chronic musculoskeletal pain in adults. Cochrane Database Syst. Rev. 20 (1), CD005956.

King, N., 2011. In: Interviews in Qualitative Research. Repr. Sage, London.

Luomajoki, H., Kool, J., de Bruin, E.D., Airaksinen, O., 2008. Movement control tests of the low back; evaluation of the difference between patients with low back pain and healthy controls. BMC Muscoskel. Disord. 9, 170.

Luomajoki, H., Kool, J., de Bruin, E.D., Airaksinen, O., 2010. Improvement in low back movement control, decreased pain and disability, resulting from specific exercise intervention. Sports Med. Arthrosc. Rehabil. Ther. Technol. 2, 11.

McLean, S., Holden, M.A., Potia, T., Gee, M., Mallett, R., Bhanbhro, S., et al., 2017. Quality and acceptability of measures of exercise adherence in musculoskeletal settings: a systematic review. Rheumatology (Oxford) 56, 426-438.

McLean, S.M., Burton, M., Bradley, L., Littlewood, C., 2010. Interventions for enhancing adherence with physiotherapy: a systematic review. Man. Ther. 15, 514-521.

Miciak, M., Gross, D.P., Joyce, A., 2012. A review of the psychotherapeutic 'common factors' model and its application in physical therapy: the need to consider general effects in physical therapy practice. Scand. J. Caring Sci. 26, 394-403.

O'Cathain, A., Thomas, K.J., Drabble, S.J., Rudolph, A., Hewison, J., 2013. What can qualitative research do for randomised controlled trials? A systematic mapping review. BMJ open 3.

O'Keeffe, M., Purtill, H., Kennedy, N., Conneely, M., Hurley, J., O'Sullivan, P., et al., 2016. Comparative effectiveness of conservative interventions for nonspecific chronic spinal pain: physical, behavioral/psychologically informed, or combined? A systematic review and meta-analysis. J. Pain 17, 755-774.

O'Sullivan, P., Caneiro, J.P., O'Keeffe, M., O'Sullivan, K., 2016. Unraveling the complexity of low back pain. J. Orthop. Sports Phys. Ther. 46, 932-937.

Palazzo, C., Klinger, E., Dorner, V., Kadri, A., Thierry, O., Boumenir, Y., et al., 2016. Barriers to home-based exercise program adherence with chronic low back pain: patient expectations regarding new technologies. Ann. Phys. Rehabil. Med. 59, 107-113.

Roland, M., Morris, R., 1983. A study of the natural history of back pain. Part I: development of a reliable and sensitive measure of disability in low-back pain. Spine 8, 141-144.

Saner, J., Kool, J., Sieben, J.M., Luomajoki, H., Bastiaenen, C.H., de Bie, R.A., 2015. A tailored exercise program versus general exercise for a subgroup of patients with low back pain and movement control impairment: a randomised controlled trial with oneyear follow-up. Man Ther 20, 672-679.

Slade, S.C., Molloy, E., Keating, J.L., 2009. 'Listen to me, tell me': a qualitative study of partnership in care for people with non-specific chronic low back pain. Clin. Rehabil. 23, 270-280.

Slade, S.C., Patel, S., Underwood, M., Keating, J.L., 2014. What are patient beliefs and perceptions about exercise for nonspecific chronic low back pain? A systematic review of qualitative studies. Clin. J. Pain 30, 995-1005.

Sokunbi, O., Cross, V., Watt, P., Moore, A., 2010. Experiences of individuals with chronic low back pain during and after their participation in a spinal stabilisation exercise programme - a pilot qualitative study. Man. Ther. 15, 179-184.

Stratford, P.G.C., Westaway, M., Binkley, J., 1995. Assessing disability and change on individual patients: a report of a patient specific measure. Physiother. Can. 47, 258-263.

Tong, A., Sainsbury, P., Craig, J., 2007. Consolidated criteria for reporting qualitative research (COREQ): a 32-item checklist for interviews and focus groups. Int. J. Qual. Health Care J. Int. Soc. Qual. Health Care/ISQua. 19, 349-357.

Van Dillen, L.R., Norton, B.J., Sahrmann, S.A., Evanoff, B.A., Harris-Hayes, M., Holtzman, G.W., et al., 2016. Efficacy of classification-specific treatment and adherence on outcomes in people with chronic low back pain. A one-year follow-up, prospective, randomized, controlled clinical trial. Man. Ther. 24, 52-64.

WHO, 2003. Adherence to Long-term Therapies: Evidence for Action. I.WHO Adherence to Long Term Therapies Project. II. Global Adherence Interdisciplinary Network. WHO Library Cataloguing-in-Publication Data. 